\title{
Investigation of the Effects of Profile Shift in Helical Gear Mechanisms with Analytical and Numerical Methods
}

\author{
Gultekin Karadere1, Ilhan Yilmaz ${ }^{1,2}$ \\ ${ }^{1}$ Department of Mechanical Engineering, Faculty of Engineering, Uludag University, Bursa, Turkey \\ ${ }^{2}$ Borcelik Celik Sanayii Ticaret A.S., Bursa, Turkey \\ Email: karadere@uludag.edu.tr, ilyilmaz@borcelik.com
}

How to cite this paper: Karadere, G. and Yilmaz, I. (2018) Investigation of the Effects of Profile Shift in Helical Gear Mechanisms with Analytical and Numerical Methods. World Journal of Mechanics, 8 , 200-209.

https://doi.org/10.4236/wjm.2018.85015

Received: February 1, 2018

Accepted: May 19, 2018

Published: May 22, 2018

Copyright $\odot 2018$ by authors and Scientific Research Publishing Inc. This work is licensed under the Creative Commons Attribution International License (CC BY 4.0).

http://creativecommons.org/licenses/by/4.0/

\begin{abstract}
In this paper, the effects of profile shift in cylindrical helical gear mechanisms have been investigated with numerical and analytical calculations. The mathematical model for computer simulation of gears has been designed and the numerical calculations have been carried out. Analytical calculations have been made with an excel program which was designed at different profile shift coefficients for a selected mechanism. Analytical calculations of the same mechanism have been verified by using ANSYS 14.5. The results of analytical and numerical solutions have been compared to profile shift coefficients.
\end{abstract}

\section{Keywords}

Profile Shift, Cylindrical Helical Gears, Tooth Root Stress, Hertzian Contact Stress, Finite Element Analysis, ANSYS

\section{Introduction}

Cylindrical gears are essential machine elements and widely used in many fields, such as wind power, coastal ships, automotive products, and general gear boxes. The helical gears offer considerable advantages for high speed and heavy-duty gear drives. For helical gears the total contact ratio is higher owing to the axial tooth overlap. Helical gears, therefore, tend to have greater load-carrying capacity compared with spur gears which material, quality of manufacture, lubrication, type of loading, and other factors are the same. They also possess the ability to a much smoother and quieter running [1] [2].

Helical gears produce an end thrust along the axis of the shafts in addition to 
the separating and tangential (driving) loads of spur gears, where suitable means can be provided to take this thrust, such as thrust collars or ball or tapered-roller bearings; it is no great disadvantage. The axial load increases as the helix angle increases. Helix angles typically range from $15^{\circ}$ to $45^{\circ}$. At high values of helix angle (for $45^{\circ}$ ), the improvement in noise tends to peak [3].

There are two basic strength calculations for two primary fatigue related failure modes in the design of gear. The first is to calculate the maximum bending stress which leads to fracture at the root of the gear tooth. The most common type of surface failure is pitting which is caused by the repeating high contact stress (Hertz surface pressure). The second job is to calculate the maximum surface pressure [3].

Profile shift is used by designers for many reasons including the elimination of undercut when hobbing or shaping gears with few teeth, increasing the load carrying capacity or the lifetime of the gears, decreasing the noise level, increasing or decreasing the center distance and changing tooth thickness. Profile shift-sometimes known as "addendum modification" - is the displacement of the basic rack (or cutting tool) datum line from the reference diameter of the gear. The size of the profile shift is usually made to be non-dimensional by dividing it by the normal module, and it is then defined by the profile shift coefficient " $x$ ". A positive profile shift increases the tooth thickness while a negative profile shift reduces tooth thickness.

Some of the studies done recently on profile shift in cylindrical gear mechanisms have been mentioned below.

Antal et al. presented a new method for the determination of the specific addendum modifications at helical gears. The method is based on the equalization of the relative velocities at the points where the meshing of the teeth begins and ends [4].

Senthil Kumar et al. worked on optimization of asymmetric spur gear drives to improve the bending load capacity. They concluded that the optimum value of profile shift coefficient for pinion increased with the increase in the values of speed ratio and teeth number in pinion [5].

Mallesh et al. investigated the effect of profile shift in asymmetric spur gears on tooth root bending stress by finite element analysis [6].

Magalhaes et al. investigated the influence of tooth profile and oil formulation on gear power loss. In the study mentioned the power losses reduction has been obtained using two different approaches: using lower modulus helical gears and significant positive profiles shifts and using gear oil formulations with different base oils [7].

Baglioni et al. investigated the influence of the addendum modification on spur gear efficiency [8].

Li et al. worked on optimal selection of addendum modification coefficients of involute cylindrical gears [9].

In this paper, the effects of profile shift in cylindrical involute helical gear mechanisms have been investigated with numerical and analytical calculations. 
The mathematical model for computer simulation of helical gears has been designed and the numerical calculations have been carried out. Analytical calculations were made with an excel program which was designed at different profile shift coefficients for a selected gear mechanism. Analytical calculations of the same mechanism were verified by using ANSYS 14.5. In this paper, the effects of profile shift coefficient on parameters such as center distance, normal pressure angle, transverse contact ratio, pinion tooth root stress, gear tooth root stress, Hertzian contact stress (surface pressure at tooth flank) in helical gear mechanisms have been investigated with numerical and analytical methods. Analytical solutions have been carried out according to DIN 3990. Numerical solutions have been performed using the finite element method. The most realistic modeling of the operation of the all gear mechanism has been done with the aid of three-dimensional finite-element analysis. It has also not been applied any external load. The results of analytical and numerical solutions have been compared to profile shift coefficients [10].

\section{Methodology}

In analytical solutions, initially, module and other size calculations are done for helical gear mechanism given in Table 1. In gear systems, there has not been any change except profile shift coefficients. Input parameters of gear systems, the main geometric dimensions and tooth forces remained constant. Center distances, pressure angles, transverse contact ratios, pinion tooth root stresses, gear tooth root stresses, Hertzian contact stresses have been calculated according to DIN 3990.

According to the data in Table 1, the module and the number of teeth of gear were chosen as $m=5$ and $z_{g}=59$. Pinion profile shift coefficient $\left(x_{p}\right)$ is selected according to the following equation proposed by DIN 3992 where $x_{g}$ represents gear profile shift coefficient [11].

Table 1. Properties of selected in volute helical gear mechanism.

\begin{tabular}{ccc}
\hline Input power & $P$ & $45 \mathrm{~kW}$ \\
Input speed & $n_{1}$ & $1500 \mathrm{rpm}$ \\
Output speed & $n_{2}$ & $410 \mathrm{rpm}$ \\
Normal pressure angle & $\alpha_{n}$ & $20^{\circ}$ \\
Helix angle & $\beta$ & $15^{\circ}$ \\
Number of teeth of the pinion & $z_{p}$ & 16 \\
Facewidth/Reference diameter & $\psi_{d}=\mathrm{b} / \mathrm{d}$ & 0.7 \\
Material of the pinion & & 20 MnCr5 (Case-hardening steel) \\
Material of the gear & & MnCr5 (Case-hardening steel) \\
Drive system & & Moderate impact \\
Operating conditions & &
\end{tabular}




$$
x_{p} \approx \frac{x_{p}+x_{g}}{2}+\left(0.5-\frac{x_{p}+x_{g}}{2}\right) \cdot \frac{\log \left(\frac{z_{g}}{z_{p}}\right)}{\log \left(\frac{z_{p} \cdot z_{g}}{100}\right)}
$$

Thus, tooth root stresses for the pinion and the gear have been expected in the near values. The most frequently used numerical method is the finite element method, as can be seen from many papers [12]. Numerical solutions were made with the program ANSYS 14.5.

Tooth geometries were made according to dimensional solutions obtained during analytical calculations. Accordingly, tooth geometry change of the pinion depending on profile shift coefficient is shown in Figure 1.

In finite element analysis, for the purpose of the closest modeling to the actual situation, the whole gear mechanism is modeled as three-dimensional to prevent application of an external force. In finite element models of geometries, ANSYS SOLID 186 elements with 20 nodes were used.

In all models examined, edges of the elements have generally a length of 2 $\mathrm{mm}$. In tooth regions where are in contact with each other, edges of the elements have a length of $0.5 \mathrm{~mm}$. The $0.5 \mathrm{~mm}$ of edge length has been defined based on a grid independence study and the details of this study can be found in Table 2.

The total number of nodes for each model is over two million. The total number of elements is over five hundred thousand. The finite element model created for non-shifted gear mechanism is shown in Figure 2.

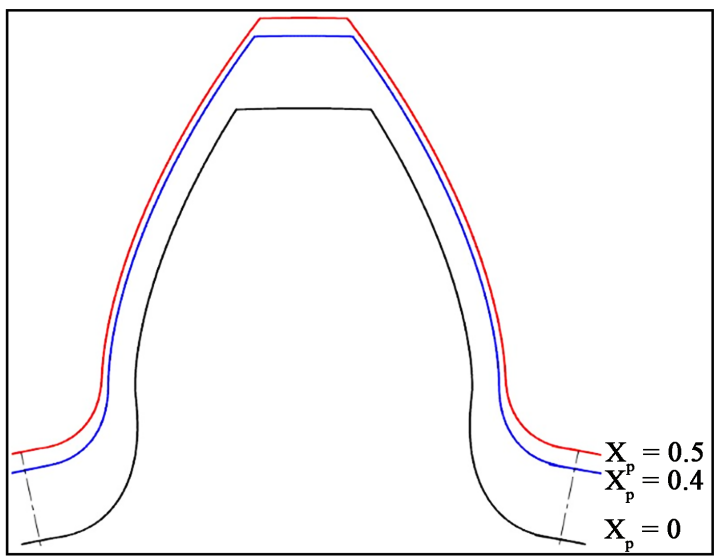

Figure 1. Influence of pinion profile shift coefficient on the pinion tooth geometry (for numerical solution).

Table 2. Grid independece study of the non-shifted case.

\begin{tabular}{ccc}
\hline Edge length $(\mathrm{mm})$ & $\sigma_{p}(\mathrm{MPa})$ & $\sigma_{g}(\mathrm{MPa})$ \\
\hline 0.25 & 76.41 & 66.56 \\
0.5 & 76.57 & 66.08 \\
0.75 & 77.81 & 69.79 \\
1 & 79.27 & 77.18 \\
2 & 107.78 & 81.35 \\
\hline
\end{tabular}




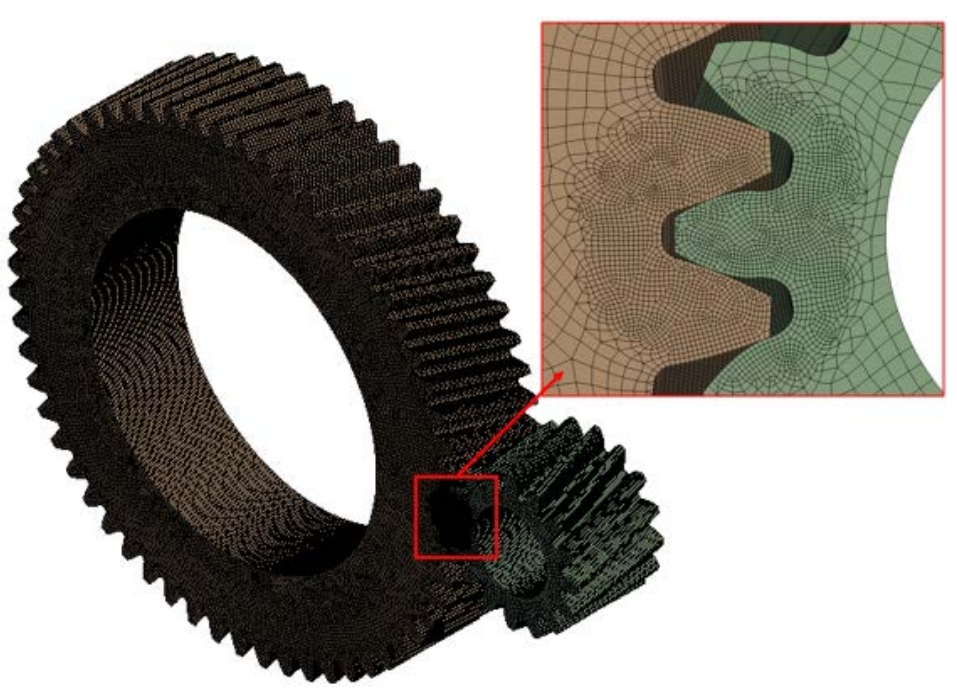

Figure 2. Finite element model for non-shifted gear mechanism (discretization of the volume by finite elements).

At analytical solution, input torque is calculated as

$$
T_{1}(\mathrm{~N} \cdot \mathrm{m})=\frac{9550 \times P(\mathrm{~kW})}{n_{1}(\mathrm{rpm})}=\frac{9550 \times 45}{1500}=286.624(\mathrm{~N} \cdot \mathrm{m})
$$

In the central part of the pinion (colored red), torque is applied clockwise. All degrees of freedom of blue surface in the middle of the gear are restricted in order to maintain balance and to read stresses in analysis (Figure 3 ).

In meshing surfaces of teeth, frictionless contacts are defined as target (colored blue) and contact (colored red) (Figure 4). Thus, the teeth surfaces can slide over one another and leave each other. In models, due to contacts, the nonlinear analysis was performed for solutions.

\section{Results}

Profile shift coefficient for each mechanism was implemented by increasing or decreasing $x=0.1$ for models used in the analytical solution. Results of all the mechanisms calculated in these values are shown in Table 3 where $\sigma_{p}, \sigma_{g}$ and $\sigma_{H}$ represents the tooth root stress of pinion, tooth root stress of gear and Hertzian contact stress respectively. $x_{t}$ is the total profile shift coefficient.

In the analytical calculation, numerical solutions are made for four different gear mechanisms. These are negative shifted $\left(x_{t}=-0.5\right)$, non-shifted $\left(x_{t}=0\right)$, and positive shifted $\left(x_{t}=+0.5\right.$ and $\left.x_{t}=+1\right)$ gear mechanisms. Maximum tooth root stress and Hertzian contact stress for each solution is calculated. The results which are obtained by solving the general equation of motion in ANSYS software are given in Table 4.

The distribution of stress on the teeth for couple and pinion in case of non-shifted gear mechanism are shown in Figure 5. Hertzian pressure distribution on the tooth surface of pinion for different profile shift values are shown in Figure 6. 
A Fixed Support

B Moment: $286.62 \mathrm{~N} \cdot \mathrm{m}$

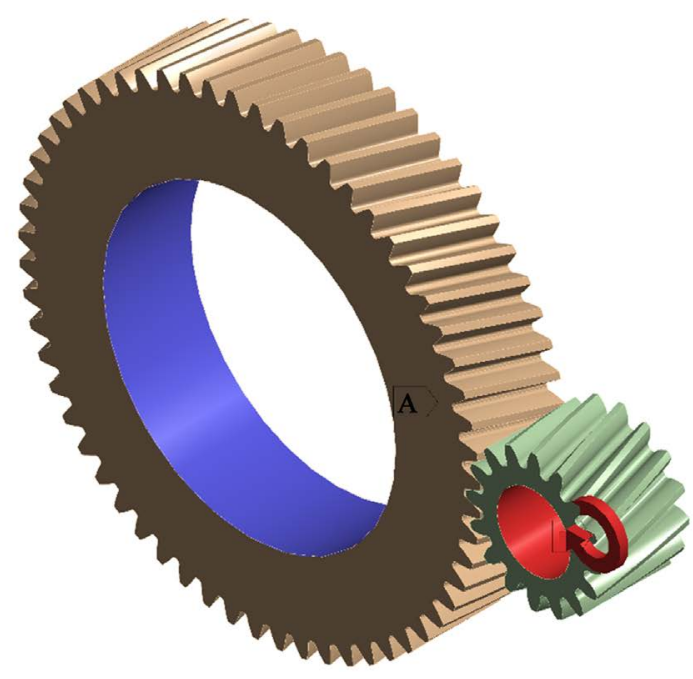

Figure 3. Boundary conditions.

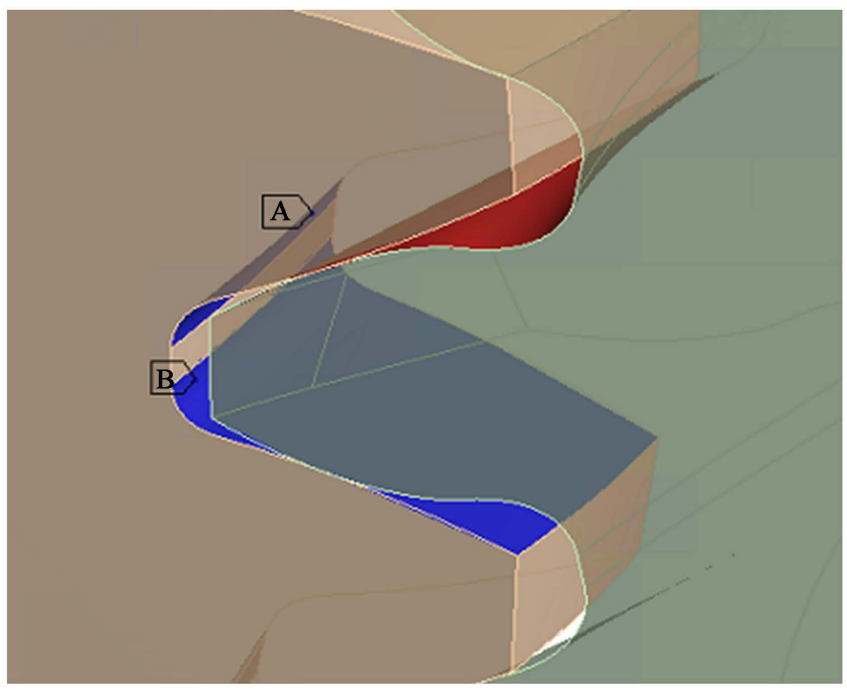

Figure 4. Contact surfaces.
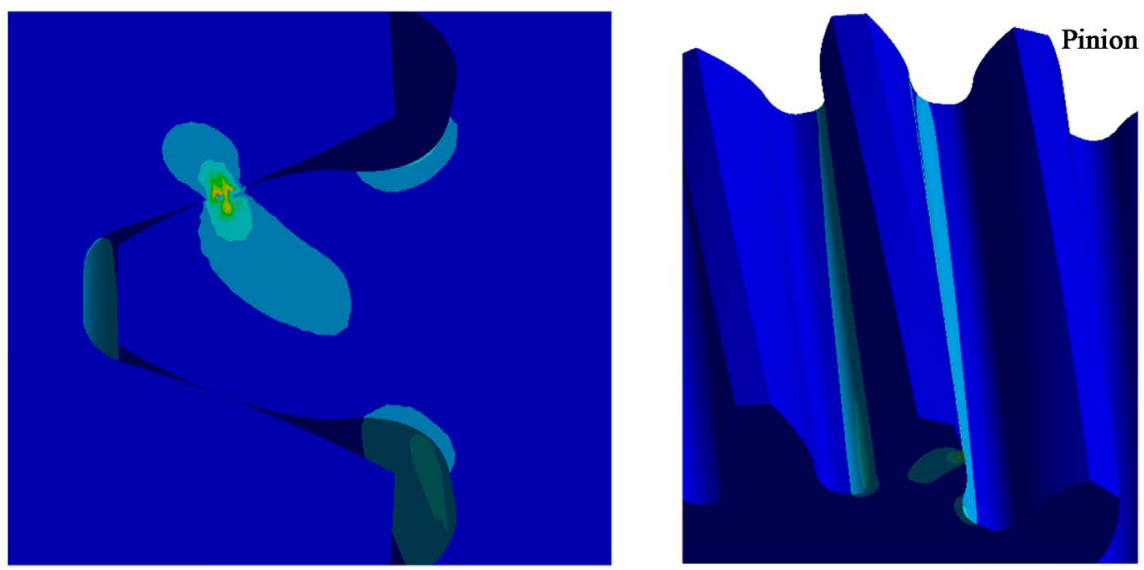

Type: Equivalent (von-Mises) Stress Unit: MPa

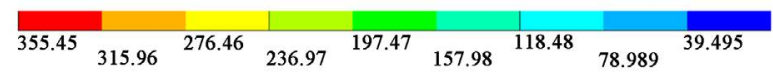

Figure 5. The distribution of von-Mises stress on the teeth for couple and pinion. 

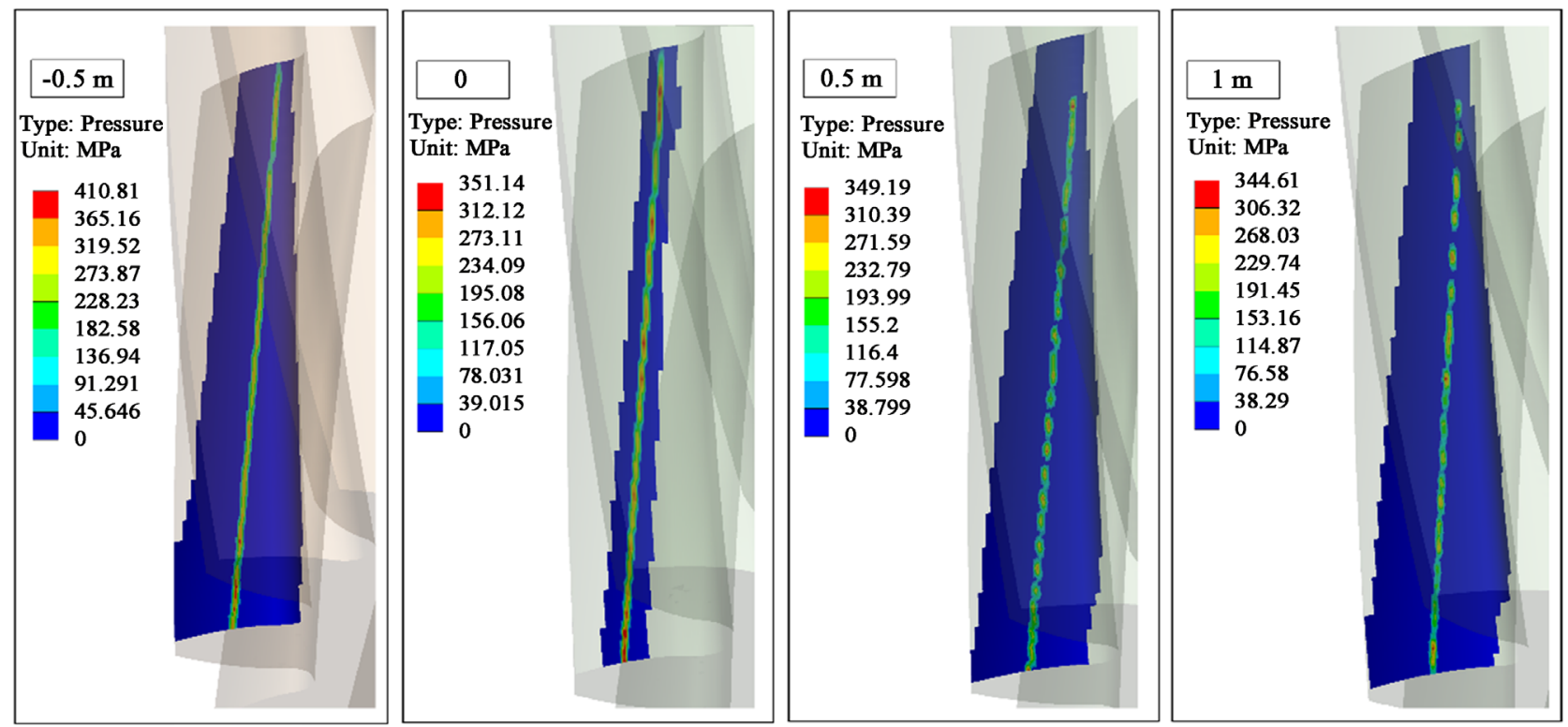

Figure 6. Hertzian pressure distribution on the tooth surface of pinion for different profile shift values.

Table 3. Analytical solution results for profile shifted gear mechanisms.

\begin{tabular}{cccccc}
\hline$x_{t}$ & $x_{p}$ & $x_{g}$ & $\sigma_{p}(\mathrm{MPa})$ & $\sigma_{g}(\mathrm{MPa})$ & $\sigma_{H}(\mathrm{MPa})$ \\
\hline-0.5 & 0.19 & -0.69 & 86.29 & 92.00 & 555.87 \\
-0.4 & 0.21 & -0.61 & 85.34 & 90.10 & 547.55 \\
-0.3 & 0.23 & -0.53 & 83.75 & 86.29 & 540.26 \\
-0.2 & 0.25 & -0.45 & 83.12 & 84.07 & 533.95 \\
-0.1 & 0.27 & -0.37 & 82.48 & 81.85 & 527.71 \\
0 & 0 & 0 & 96.76 & 72.97 & 522.50 \\
0.1 & 0.31 & -0.21 & 79.95 & 78.36 & 517.53 \\
0.2 & 0.33 & -0.13 & 79.31 & 77.09 & 512.85 \\
0.3 & 0.35 & -0.05 & 78.68 & 74.24 & 508.41 \\
0.4 & 0.37 & 0.03 & 77.72 & 72.65 & 504.17 \\
0.5 & 0.40 & 0.10 & 75.82 & 72.33 & 500.38 \\
0.6 & 0.42 & 0.18 & 75.19 & 70.75 & 496.76 \\
0.7 & 0.44 & 0.26 & 74.24 & 69.79 & 493.17 \\
0.8 & 0.46 & 0.34 & 73.28 & 68.84 & 490.02 \\
0.9 & 0.48 & 0.42 & 72.65 & 67.89 & 486.81 \\
1 & 0.50 & 0.50 & 71.70 & 66.94 & 483.99 \\
\hline
\end{tabular}

Table 4. Numerical solution results for profile shifted gear mechanisms.

\begin{tabular}{cccccc}
\hline$X_{t}$ & $X_{p}$ & $X_{g}$ & $\sigma_{p}(\mathrm{MPa})$ & $\sigma_{g}(\mathrm{MPa})$ & $\sigma_{H}(\mathrm{MPa})$ \\
\hline-0.5 & 0.19 & -0.69 & 69.65 & 74.66 & 410.81 \\
0 & 0 & 0 & 76.57 & 66.08 & 363.95 \\
0.5 & 0.40 & 0.10 & 67.87 & 67.50 & 349.19 \\
1 & 0.50 & 0.50 & 66.98 & 65.60 & 344.61 \\
\hline
\end{tabular}


The following conclusions have been reached in the analytical solution. According to non-shifted gear mechanism, the center distance has decreased approximately $0.27 \%$ for negative profile shift of each $x=-0.1$. According to non-shifted gear mechanism, the center distance has increased approximately $0.25 \%$ for positive profile shift of each $x=+0.1$.

According to non-shifted gear mechanism, the pressure angle has decreased approximately $2.24 \%$ for negative profile shift of each $x=-0.1$. According to non-shifted gear mechanism, the pressure angle has increased approximately $1.88 \%$ for positive profile shift of each $x=+0.1$.

Due to small number of teeth of the pinion, only positive profile shift is applied to prevent undercut in pinion. According to non-shifted gear mechanism, the pinion tooth root stress has decreased approximately $5.44 \%$ for positive profile shift of each $x=+0.1$.

According to non-shifted gear mechanism, the gear tooth root stress has increased approximately $3.63 \%$ for negative profile shift of each $x=-0.1$. According to non-shifted gear mechanism, the gear tooth root stress has decreased approximately $1.52 \%$ for positive profile shift of each $x=+0.1$.

According to non-shifted gear mechanism, Hertzian contact stress has increased approximately $1.14 \%$ for negative profile shift of each $x=-0.1$. According to non-shifted gear mechanism, Hertzian contact stress has decreased approximately $0.83 \%$ for positive profile shift of each $x=+0.1$.

Profile shift coefficient for each mechanism was implemented by increasing or decreasing $X=0.5$ for models used in the numerical solution.

Tooth root stresses and Hertzian contact stresses are increased with negative profile shift, while they are decreased with positive profile shift.

Compared to the numerical simulation results, the pinion tooth root stress has decreased approximately $3.42 \%$ for each $x=+0.1$ positive profile shift coefficient, according to non-shifted gear mechanism.

If the analytical and the numerical results are compared, the analytical results are found to be at higher values. This is because the analytical calculation is done for the most critical case. As seen from Figure 7 and Figure 8, the analytical-numerical result differences from negative profile shifting towards positive profile shifting have been decreased.

While the difference for tooth root stress of non-shifted pinion is $20.72 \%$, the difference is $6.58 \%$ for positive shifted pinion of $x_{p}=0.5$ (Figure 7). While the difference for tooth root stress of negative shifted gear of $x_{g}=-0.69$ is $18.85 \%$, the difference is $2 \%$ for positive shifted gear of $x_{g}=0.5$ (Figure 8). As seen from Figure 9, Hertzian contact stresses in the analytical solution have been decreased approximately $28 \%$ compared to numerical results.

\section{Conclusion}

Consequently, in this study, the results of the analytical solution, have been found to be larger according to the results of the numerical solution. The differences of tooth root stresses found through analytical and numerical methods is 


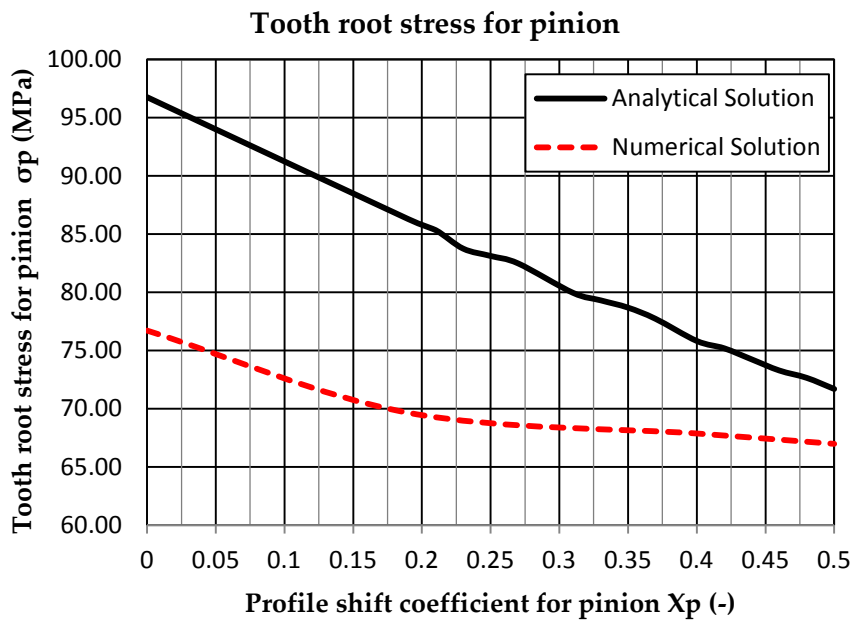

Figure 7. Influence of pinion profile shift coefficient on pinion tooth root stress (Comparison of analytical and numerical solutions).

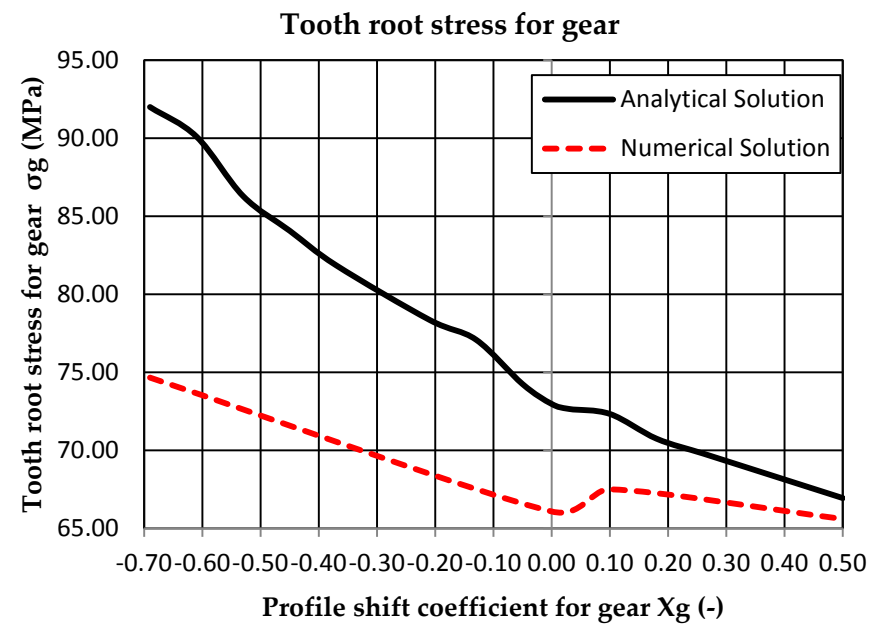

Figure 8. Influence of gear profile shift coefficient on gear tooth root stress (Comparison of analytical and numerical solutions).

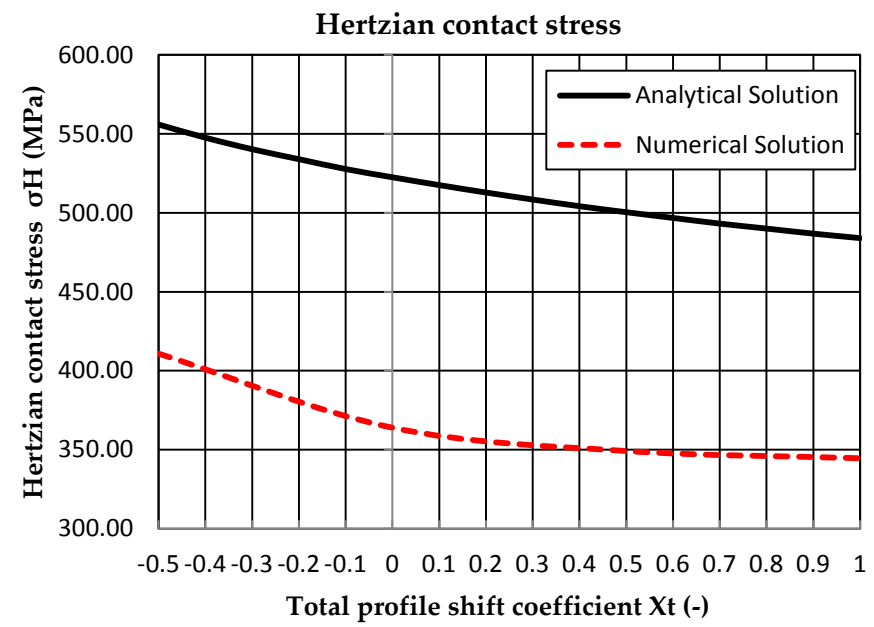

Figure 9. Influence of total profile shift coefficient on Hertzian contact stress (Comparison of analytical and numerical solutions). 
gradually decreased in the direction of a positive shift. Hertzian contact stress differences between the two solutions, have been remained almost the same. However, the differences are much greater compared to the tooth root stresses. The effect of profile shifting on tooth root stresses, is larger than in Hertzian contact stresses. The effect of negative profile shifting on especially tooth root stresses, is larger than in positive profile shifting. Selecting the appropriate profile shift coefficients, the fatigue strength and service life of gears can be increased as mentioned in the references. Similarly, vibrations and noise can be reduced. Similar theoretical studies/practical research results such as this article will guide the designer in design decisions process.

\section{References}

[1] Hamrock, B.J., Schmid, S.R. and Jacobson, B.O. (2006) Fundamentals of Machine Elements. McGraw-Hill Education, New York, 673-674.

[2] Maitra, G.M. (2008) Handbook of Gear Design. McGraw-Hill Education, New Delhi, 11-12.

[3] Shigley, J.E. and Mischke, C.R. (1996) Machine Design. McGraw-Hill Education, New York

[4] Antal, T.A., Antal, A. and Arghir, M. (2008) Determination of the Addendum Modification at Helical Gears, at the Points Where the Meshing Starts and Ends, Based on the Relative Velocity Equalization Criterion. 79 th Annual Meeting of the International Association of Applied Mathematics and Mechanics (GAMM), Bremen, December 2008, 10965-10966. https://doi.org/10.1002/pamm.200810965

[5] Senthil Kumar, V., Muni, D.V. and Muthuveerappan, G. (2008) Optimization of Asymmetric Spur Gear Drives to Improve the Bending Load Capacity. Mechanism and Machine Theory, 43, 829-858.

https://doi.org/10.1016/j.mechmachtheory.2007.06.006

[6] Mallesh, G., Math, V.B., Ashwij, Dutt, R.P.S. and Shanbhag, R. (2009) Effect of Tooth Profile Modification in Asymmetric Spur Gear Tooth Bending Stress by Finite Element Analysis. 14th National Conference on Machines and Mechanisms (NaCoMM09), Durgapur, 17-18 December 2009, 62-67.

[7] Magalhaes, L., Martins, R., Locateli, C. and Seabra, J. (2010) Influence of Tooth Profile and Oil Formulation on Gear Power Loss. Tribology International, 43, 1861-1871. https://doi.org/10.1016/j.triboint.2009.10.001

[8] Baglioni, S., Cianetti, F. and Landi, L. (2012) Influence of the Addendum Modification on Spur Gear Efficiency. Mechanism and Machine Theory, 49, 216-233. https://doi.org/10.1016/j.mechmachtheory.2011.10.007

[9] Li, X., Jiang, S. and Zeng, Q. (2013) Optimal Selection of Addendum Modification Coefficients of Involute Cylindrical Gears. Journal of Computers, 8 2156-2161. https://doi.org/10.4304/jcp.8.8.2156-2161

[10] Yilmaz, I. (2013) Investigation of the Effect of Profile Shifting in Helical Gear Mechanisms with Analytical and Numerical Methods. M.Sc. Thesis, Graduate School of Natural and Applied Science, Uludag University, Bursa. (In Turkish)

[11] German Institute for Standardization (1964) Addendum Modification of External Spur and Helical Gears (DIN 3992). Berlin.

[12] Mackerle, J. (1999) Finite Element Analysis of Machine Elements: A Bibliography (1977-1997). Engineering Computations, 16, 677-748.

https://doi.org/10.1108/02644409910286429 